Gestão e Desenvolvimento, 21 (2013), 83-100

\title{
O DESENVOLVIMENTO POR MÚLTIPLOS CAMINHOS
}

\author{
Maria Olívia Dias
}

\begin{abstract}
Resumo: Este artigo procura demonstrar que o conceito de crescimento não é sinónimo de desenvolvimento. Apresenta uma tipologia de modelos que na prática seguem caminhos diferentes de desenvolvimento. São analisados quatro modelos: $O$ modelo da modernização, da independência, da aliança popular e o modelo da negociação cultural. $O$ modelo da Modernização tem como protagonista o empreendedor, preocupa-se com o aumento da produtividade, tem uma dimensão quase exclusivamente económica e está ligado ao sistema capitalista. O modelo da Independência tem como protagonista o político, defende o partido único, um Estado/Nação, segue o sistema nacionalista. No modelo da Aliança Popular o protagonista é o povo, na sua base estão os pobres, acredita-se que a sua libertação acontece só na presença de um movimento nacional, tem uma dimensão mais organizativa semelhante ao sistema comunista. O modelo da Negociação Cultural vem entendido em relação à sua capacidade de diálogo entre as diferentes culturas, põe a ênfase na cultura e na integração das diferentes culturas para um desenvolvimento integral e sustentável, é o modelo mais completo. Baseia-se num conceito de desenvolvimento que passa por um processo de mudança contínuo de envolvimento $e$ participação orientado pelo sistema democrático. Concluímos com a necessidade de reconhecer os limites das tecnologias associadas aos modelos e a importância que a ética tem na prática dos modelos de desenvolvimento.
\end{abstract}

Palavras-chave: Crescimento, Desenvolvimento, Modernização, Independência, Aliança Popular, Negociação Cultural.

\begin{abstract}
This article seeks to demonstrate that growth and development concept are not synonymous of development. It presents a typology of models that in practice follow different pathos of development. There were analyzed four models: model of
\end{abstract}

\footnotetext{
* Docente da Universidade Católica Portuguesa - Centro Regional das Beiras - Viseu. E-mail: profaoliviadias@gmail.com.
} 
modernization; model of independence; model of popular alliance and model of cultural negotiation. The model Modernization has its main character in the entrepreneur concerned with increasing productivity exclusively with an economic dimension and connected with the capitalist system. The Independence model has its main character in the politician, a one party policy, State/Nation supporter that follows the nationalist system. In the model of Popular Alliance the people are the main characters, the basis are the poor, it believes that the poor liberation only happens with a national movement, it has an organized dimension near to the to the communist system. The Cultural Negotiation model is understood in its ability for dialogue between different cultures, to achieve integrated and sustainable development, it's the most complete model based on a concept of development through a process of continuous change and democratization towards the democratic system. We conclude that the need to recognize the boundaries of technologies and the importance of ethics should be applied to the development of these models.

Keywords: Growth, Development, Modernization, Independence, Popular Alliance, Cultural Negotiation

\section{INTRODUÇÃO}

Qualquer que seja o caminho do desenvolvimento é para o Bem Comum, não é de um tipo de pessoa ou grupo. $O$ tipo de escolha que se fizer é para soluções do Homem e de Todos os homens.

O debate acerca dos caminhos, dos seus aspetos positivos e negativos, bem como os limites de cada um, passam por manifestações de esgotamento denunciadas muitas vezes pelo modelo ou pelos modelos de desenvolvimento desacreditados porque as intervenções que cada um faz a nível da população, da produção de alimentos, de recursos técnicos e humanos, do controlo ambiental, etc., não conduzem a uma visão global e integral do desenvolvimento. Isto porque as tensões e as perspetivas se contrapõem umas às outras em função dos interesses individuais que se sobrepõem às preocupações locais ou mesmo mundiais.

Deste modo, é possível observarmos vários caminhos mas incapazes de construírem as respostas que tanto os países ricos como os pobres esperam. É claro que não podemos universalizar um determinado modelo, mas sim modelos que procurem complementar-se porque há diferentes modos de sentir a cultura, as vivências, as práticas sociais, mas há um país, um mundo global e globalizado que se deve conduzir para toda a 
Humanidade e por isso é essencial um desenvolvimento integral e não parcial (Lopes, ${ }^{5}$ 2001).

Dito isto, procuraremos num primeiro ponto distinguir crescimento e desenvolvimento, de seguida analisaremos quatro tipos de desenvolvimento: a modernização; a independência; o movimento da aliança popular e o modelo da negociação cultural.

Tendo em consideração os limites de um artigo o enfoque é colocado no conjunto dos caminhos que nos parecem representar a melhor interpretação para o desenvolvimento, sem perder de vista os aspetos positivos e negativos de cada um. Concluímos fazendo a síntese de cada modelo e os limites, sem todavia deixarmos de fazer uma breve referência à ética associada aos modelos de desenvolvimento propostos.

\section{DESENVOLVIMENTO OU CRESCIMENTO}

Durante longos anos foi muito comum abordar o desenvolvimento como sinónimo de crescimento económico, por vezes simplificando as formas de medir o desenvolvimento, tendo em consideração quase exclusivamente os indicadores tradicionais da economia (produto interno bruto, mercado, etc.), assim vinham por um lado explicados os aspetos culturais e sociais, e, por outro, os estruturais e ecológicos.

Nesta perspetiva clássica o desenvolvimento confundia-se com o crescimento económico, que pode ser definido como o incremento duradouro de uma unidade económica, simples e complexa, realizado nas mudanças e nas estruturas (e eventualmente de sistema) acompanhado de progressos económicos. Diligencia-se principalmente o impacto do desenvolvimento sobre a condição humana (Darling, 1971, apud, Gazeneuve \& Victoroff, 1982: 258,259).

$\mathrm{O}$ conhecimento que aqui pretendemos trazer dirige-se para a dimensão não tanto do crescimento mas realçar a dimensão do desenvolvimento. Justifica-se esta abordagem, porque embora seja inegável a sua correlação entre crescimento económico e desenvolvimento sendo que os dois contribuem para a perceção que fazemos das desigualdades nos dois sentidos, ou seja, colocamos a tónica em relação a países desenvolvidos e subdesenvolvidos, mas também dentro dos próprios países, onde por vezes se observam demasiados eufemismos que contribuem para mascarar os problemas, as causas diretas ou indiretas que dependem uns dos outros qualquer que seja a sociedade, mais desenvolvida ou menos desenvolvida.

Um certo obscurantismo das consciências conduzem a certos riscos que ninguém quer ver nas dinâmicas e estruturas de cada sociedade em 
particular e do mundo em geral. De facto, a obsessão cria miopia e por isso o desenvolvimento desafia o crescimento orientado para toda a Humanidade.

O conhecimento triunfará, mas não basta, é preciso encorajar e reforçar cada vez mais este conhecimento para satisfazer e otimizar o desenvolvimento através de uma clara atuação em relação a todos os problemas das pessoas e não só de algumas (Toffler, 1984; 1991).

Compreendemos agora porque se falou no passado, fala-se no presente e falar-se-á no futuro do crescimento económico, do progresso, mas falar-se-á também no futuro acentuando sempre o desenvolvimento porque os problemas das pessoas, tanto a nível local como mundial são cada vez mais complexos exigindo adequação a respostas mais globais e mais rápidas.

De facto, esta complexidade é cada vez mais global, manifestando-se as rivalidades que só fabricam pobreza, desigualdades dão poder a uns e tiram-no a outros, as desigualdades entre países desenvolvidos e subdesenvolvidos, restringindo as relações que se deviam mover por uma Humanidade inteira assumindo que na sociedade uns tem muita influência e outros estão sujeitos a ser influenciados, quase por obrigação. Ora não é isto que o desenvolvimento ordena para os problemas do Homem, mas sim fazer as sociedades mais justas e humanas para todos (David, 1981).

Esta abordagem conduz-nos a atitudes da esfera da solidariedade, de uma dimensão não economicista e individualista, na sua vertente quantitativa, mas sobretudo uma dimensão qualitativa virada mais para o desenvolvimento qualitativo (Alberoni, ${ }^{6} 2000$ ). Existem pessoas mais próximas do sofrimento, da fome, das doenças, das desigualdades e injustiças sociais, que estão efetivamente presentes no modo como o desenvolvimento é percecionado pelos governantes do mundo. É por isso que não nos podemos resignar tendo como obrigação projetar e orientar o desenvolvimento, segundo critérios científicos, utilizando todos os instrumentos para resolver os problemas do mundo que passam não só pela economia, mas também por valores conscientes, éticos, morais, políticos, sociais, existencialistas e culturais que empobrecem e dificultam o desenvolvimento que conduz a uma maior satisfação no mundo (Perroux, 1981; Pierre, 2001; Silva, 1985; Taylor, 2001).

Neste sentido, não podemos ser minimalistas, a ciência e a tecnologia cada vez mais se tornam determinantes não só no crescimento económico, mas também no desenvolvimento de todas as regiões do mundo. É por isso que não podemos pensar em crescimento económico sem termos em conta o desenvolvimento, isto é, estes dois elementos andaram sempre de 
mãos dadas, simplesmente primeiro prestava-se maior atenção ao crescimento, sendo que, a partir da II Guerra Mundial tem havido um maior interesse pelo desenvolvimento porque é um conceito mais abrangente. É especialmente a partir daqui que se tem escrito muito sobre o desenvolvimento, cobrindo um campo mais vasto e mais complexo do que o crescimento económico, pelo facto das suas variáveis serem mais difíceis de controlar do que as do crescimento que são mais objetivas (Gritti \& Masini, 1981: 176 e ss.).

Embora como bem evidencia Francisco Dinis (2006:33): "O crescimento e o desenvolvimento caminham de mãos dadas até ao ponto em que a economia perde a sua capacidade de adaptação a novas condições". É a complementaridade e o contributo que estes dois elementos dão em conjunto para o bem-estar das pessoas.

Por conseguinte, isoladamente, nem o crescimento económico nem o desenvolvimento são capaz de rentabilizar e otimizar-se nos desafios que lhe são colocados, quantitativos mais próximos do crescimento e qualitativos mais próximos do desenvolvimento.

Assim, um modelo de desenvolvimento deve ter em conta as políticas e os valores que não sejam apenas crescimento económico, que não podemos deixar de considerar a importância que tem simultaneamente com o desenvolvimento quando fazemos uma análise dos diferentes modelos analisados a seguir.

\section{OS CAMINHOS DO DESENVOLVIMENTO}

A implementação sucessiva de novos caminhos surge porque os modelos existentes não respondem às necessidades das pessoas em particular, dos países e do mundo em geral. Espera-se que os modelos tenham estratégias globais, com interesses comuns. Cada modelo possui nas diferenças culturais, não se podem impor de fora, porque conduzem a sucessivos fracassos (Abdelmalki \& Courlet, 1996).

A este propósito, analisamos essencialmente os caminhos da Modernização, da Independência Nacional, da Aliança Popular e finalmente um quarto caminho que passa pela Negociação Sociocultural que procura combinar as diferentes culturas pelo impacto que cada um tem no desenvolvimento.

\subsection{O Caminho da Modernização}

O caminho da modernização formulado na Europa Ocidental, pretendia implementar o racionalismo europeu porque era segundo os 
seus mentores a perfeição natural da pessoa, os europeus tinham o dever de levar a civilização a todo o mundo. "Esta ideia ofereceu a base para o colonialismo, embora tanto o colonialismo espanhol como o português no séc. XVI era menos "moderno" e menos "modernizador". É importante recuperar a Revolução Industrial, a Revolução Política francesa e americana durante o séc. XIX" (Giddens, 1992: 15 e ss.; David, 1981).

No entendimento deste modelo todos os povos do mundo deviam imitar o processo do "Norte" e a racionalidade dos países industrializados, o mito de uma história linear que todas as nações deviam seguir. Ora, para estes defensores todas as culturas do mundo que se encontrassem no estado "tradicional", "teológico", "pré-capitalista"; "préindustrial" deviam desaparecer No futuro haverá uma só cultura, a cultura racional descoberta no norte do mundo (Boudon, 1995, passim; Gritti \& Masini, 1981: 73 e ss.).

Este modelo, que não passa de um mito, sublinha a importância de certos tipos de teorias reducionistas da comunicação no processo de desenvolvimento.

A metáfora central da livre concorrência no mercado é a lei do progresso. A fonte do progresso é a criatividade individual, a capacidade de descobrir alguma coisa melhor para a vida das pessoas na sociedade. Neste sentido, a fonte do progresso é a imaginação utilitarista. Obviamente, esta é uma visão idealista sobretudo do progresso da história. Desta convicção deriva a ideia e a "imaginação" funcionalista que passa por deixar que tudo responda livremente ao próprio ambiente, ao estímulo, à criatividade e à ação empreendedora Abdelmalki \& Courlet, 1996).

De facto, este modelo tem como parte central o sistema económico e quase todas as variáveis sociais e culturais se orientam para a explicação do "homo economicus", isto é, a pessoa e as instituições sociais fornecem as condições do desenvolvimento de empreendedor na concorrência do mercado (Rostow, 1960:1-12).

Esta abordagem, relacionada com as que se liga às teorias da modernização, defendem a necessidade de abandonar as sociedades tradicionais fechadas e partirmos para um desenvolvimento diferente. Isto só seria possível com uma elite de nível de educação superior, com o objetivo de criar e inovar uma nova visão na vida destas sociedades transformando-as em modernas. O capitalismo torna-se uma condição normal. $\mathrm{O}$ crescimento gera capital, novas indústrias sem a intervenção estrangeira. Existe uma classe empreendedora, motivada para a mentalidade capitalista influenciadora das populações. 
Relativamente às teorias e às aplicações empíricas não podemos deixar de considerar que qualquer que seja o caminho encontramos sempre aspetos positivos e negativos. Neste modelo recuperamos como positivos: a) a rápida constituição das instituições e estruturas organizativas do Estado Moderno.

Em poucos anos foi possível introduzir estruturas fundamentais pelo mercado capitalista: finanças, banco central com moeda nacional, sistema de crédito e empréstimo; em geral conseguiu organizar um sistema dos serviços na agricultura, saúde, educação, etc., criação de estradas, transportes e comunicação; um sistema de preparação de pessoas qualificadas para serviços que pedem pessoal qualificado nas diversas áreas; b) rápida transformação das tecnologia para solução dos grandes problemas humanos: fome, epidemias, etc. c) Criação do sistema mundial de mercado e consumo.

O resultado mais evidente é a distribuição dos bens de consumo a toda a comunidade. O principal processo de desenvolvimento é o mercado livre dos bens de consumo, das ideias, da participação política.

Na dimensão negativa temos essencialmente: a) a concentração do poder social a nível nacional e internacional assim como o aumento de injustiças no mundo. $\mathrm{O}$ aumento das injustiças, como por exemplo: a rigidez no mercado económico, o mercado das "ideias", a rigidez das estruturas sociais na sociedade com estrutura hierárquica dicotómica; b) os governantes com cultura, enquanto a população, sobretudo camponesa continuavam analfabetas. A educação da comunidade rural não era prioridade. Não admira que o aumento da dependência sociopolítica, económica e cultural dos países menos desenvolvidos fosse uma evidência (Giraud, 1998).

$\mathrm{Na}$ concorrência tecnológica, os países mais pobres continuam a fornecer matéria-prima mas os produtos sofisticados são produzidos nos países industrializados. Isto permite que os países do sul da Europa e os menos desenvolvidos continuem sempre como parte dependente do sistema político e económico mundial. Todas as decisões importantes a nível político, económico e cultural se tomam nos países desenvolvidos.

Desta forma, o modelo de transferência tecnológica é, uma forma de dependência contínua. Este modelo de transferência é a base do imperialismo político, económico e cultural, chegando-se à conclusão de que não é possível assumir que todas as culturas e os sistemas nacionais no mundo percorram o mesmo caminho de desenvolvimento. Não se pode pretender que todos os países sigam o mesmo caminho, as mesmas etapas no mesmo tempo. 
A censura à cultura ocidental, a instabilidade política, a concentração do poder, as desigualdades e as injustiças conduziram a um outro caminho com outras soluções.

Dizia Barata e Ambrósio (1988: 13): "A modernização constituída pelo salto qualitativo entre dois estados, um "antes" e um "depois" moderno é hoje necessário contrapor uma modernização como devir, como fluxo permanente de mudanças, mais rápido aqui, mais lento ali, procurando e procurando-se na busca de uma coerência - o que era moderno ontem já é antigo hoje, o que é moderno hoje será antigo amanhã ...".

\subsection{O Caminho da Independência ou da Libertação}

Se o caminho da modernização tinha uma lógica económica do "mercado livre" este tem a lógica política. O desenvolvimento é uma estratégia de mobilização e motivação da população num processo de decisão coletiva para formar uma nação - um povo que fala uma só voz em concorrência com outras nações.

As variáveis centrais são a legitimidade da decisão coletiva e o poder social, não a criatividade empreendedora como no modelo da modernização. Se este colocava como protagonista central do desenvolvimento o empreendedor, aqui o protagonista é o político e o controlo do seu partido sobre o Estado. O Estado é o instrumento para levar o desenvolvimento por diante. O Estado assume um papel quase sagrado, a incarnação da vontade do povo.

O nacionalismo emerge como modelo de sociedade cujo Estado absorve quase todas as outras instituições. O nacionalismo é também um conjunto de valores que definem "quem é o cidadão", a pessoa humana. Criar uma nação é a base das motivações para o desenvolvimento (Todaro, 1989).

No processo de formar a Nação/Estado há duas estratégias centrais: a integração interna de todas as comunidades, regiões e subculturas, num só sistema sociocultural político e económico e a diferenciação desta unidade nacional das outras nações.

O objetivo deste modelo consiste em criar estratégicas que conduzam à integração nacional onde o elemento cultural, a língua "oficial" e educação aberta a todos, controlada pelo Estado que nomeia docentes e estabelece os currículos dos estudos. Por outro lado, é fundamental criar um mercado económico único com um banco central e uma moeda nacional; criar fronteiras; criação de inimigos externos para diferenciar e integrar; segurança nacional como escolha prioritária. 
Este caminho rejeita fortemente o valor da história universal, o conceito de uma estrada unilinear do desenvolvimento. Há uma rejeição, em particular à orientação de que todas as nações devem seguir o mesmo caminho do Capitalismo da Europa Ocidental, ou seja, o caminho da modernização. Cada povo tem o direito de definir e determinar o seu próprio caminho de desenvolvimento; cada nação é "soberana" e nenhuma nação pode intervir. A capacidade de autodeterminação torna-se o objetivo central do desenvolvimento. Cada nação deve reproduzir as instituições fundamentais e o "símbolo" central é a independência política (Boudon, 1984; Todaro, 1989).

Porém, a tão desejada independência política não existe sem a economia e estas sem a cultura que também depende da comunicação. Ora a lógica da interdependência das diversas independências nacionais geraram o movimento das "Novas Ordens Mundiais", isto é, a descoberta que a independência política não significa nada se não existir a independência económica, a cultura e a comunicação (Gritti \& Masini, 1981: passim).

Em certa medida, os políticos têm "medo" da independência dos empreendedores e obviamente o partido procura criar o mito que os empreendedores não podem fazer nada sem a ajuda do Estado. Portanto, direta ou indiretamente, existe uma nacionalização económica. O Estado torna-se o principal patrão, responsável pela solução de todos os problemas, o que não acontecia no modelo anterior que oferecia serviços para aumentar a produtividade, mas não a responsabilidade com todos os problemas (Inglehart, 2001).

Ora isto significa que também este caminho se esgotou rapidamente, porque a população não obteve os resultados que pretendia, libertar-se das nações capitalistas, pensando que se organizava numa nação desenvolvida valorizando quase exclusivamente a política e desconsiderando a economia. É por isso que este caminho não produziu os efeitos que em princípio o povo esperava (Ibidem).

Tendo em conta o modelo tornam-se evidentes alguns aspetos positivos mas também alguns negativos. Quanto aos positivos podemos realçar a unidade nacional nos seus aspetos: símbolo de identidade social; diferenciação do país colonizador - rutura muito forte -; redução do conflito; motivação para construir a Nação/Estado; recompensas pessoais em termos de bem-estar comum. Um desenvolvimento em certa medida equilibrado porque um governo forte institui prioridades claras. É importante usar todos os recursos bem, e isto depende das prioridades.

Quanto aos negativos ligam-se essencialmente: à concentração do poder e à violação dos direitos pessoais e sociais, muitas energias 
nacionais consomem-se na repressão, na fuga dos intelectuais; desenvolve-se uma repressão dos movimentos populares independentes (sindicatos, operários e camponeses). A incorporação forçada de todos os movimentos e instituições numa estrutura orgânica controlada inibe o desenvolvimento de instituições democrático-participativas (Monteiro \& Ferreira, 2009).

Este caminho parece não deixar tempo ao povo para ter liberdade de escolher o que pensa ser melhor. Quando o processo se faz na base da força parece existir uma enorme hipocrisia. Durante os anos de 19601980 quase todos os grandes movimentos nacionalistas da independência caíram, desacreditando ideais propostos pelo poder de um partido único (Gritti \& Masini, 1981). A ironia deste caminho que prometia o desenvolvimento político tornou-se um fiasco político, não admira que o povo se revoltasse e procurando um outro modelo, aparecendo em oposição o movimento das culturas populares que tratamos a seguir.

\subsection{O Movimento das Culturas Populares - Aliança Popular}

A crise e as falências dos modelos anteriores conduziram a um outro caminho que tem como base o povo, tornando-se o verdadeiro coração da nação, não é o empreendedor não é o político, a base do modelo vem alargada à população toda.

Nos inícios dos anos 1970 forma-se um setor no mundo do desenvolvimento que crítica fortemente o modelo da independência focalizado no Estado. Para este movimento o povo era a força da organização de base dos pobres como protagonistas do desenvolvimento.

A ideia subjacente a estes movimentos é o facto de acreditarem que se pode criar pouco a pouco, uma base de poder contra o "centro", ou seja, através da organização de base popular seria possível levar o "centro" a mudar a sua concetualização e os seus comportamentos.

$\mathrm{O}$ verdadeiro desenvolvimento começa com a base e pode atingir-se somente através dos movimentos marginais versus centro. Não querem um poder centralizado num partido único. Deste modo, desenvolve-se a opinião que a infraestrutura de organizações populares fosse absolutamente necessária para o progresso e desenvolvimento da nação.

Tipicamente, neste modelo, forma-se uma "aliança popular" um movimento que inclui: jovens intelectuais universitários; a Igreja (s) e os dirigentes religiosos; os profissionais dos mass media; escritores, publicitários, sindicatos, etc. Para todos os participantes desta aliança a "bandeira" e o símbolo são representados pelo pobre desfrutado nos 
outros modelos de desenvolvimento (Lopes, 1999; Nunes, 2001; Gritti \& Masini, 1981).

Neste movimento na forma de organização social, todos são absolutamente iguais, não é permitido alguma distinção ou algum privilégio. Isto é o comunismo no seu momento "carismático", os movimentos "contracultura" dos jovens nos anos 60-70, que criaram grupos organizados sobre bases igualitárias e com regras de vida baseadas em princípios coletivistas. O que é importante é a relação social de igualdade.

A lógica central deste modelo é a qualidade das relações sociais que devem ser baseadas na igualdade e no respeito através das convicções que vêm de dentro das pessoas Rocher, ${ }^{3} 1980$; Rogers, 1969).

De facto, chegamos ao ponto de citar alguns teóricos da Sociologia (Durkheim, Tonnies, Max Weber, Karl Marx, Parsons, entre muitos outros, apoiantes destes movimentos populares ligados à construção da solidariedade humana autêntica, sem alienação e sem anomia, mas com uma verdadeira integração da pessoa no Grupo Humano, de modo a que cada um contribua para a solidariedade do grupo e o grupo constitua um contexto para o desenvolvimento integral de cada um. $\mathrm{O}$ argumento que justifica estes autores é que o verdadeiro problema do desenvolvimento é a "alienação" por um lado, e a "anomia" por outro (Boudon, 1995; Gritti \& Masini, 1981: passim).

Embora se torne evidente que os caminhos da Aliança Popular contribua para reforçar a legitimidade política enquanto defende uma maior participação, mais liberdade de expressão, mais igualdade, um maior uso dos protestos da organização popular de natureza pacífica, tende no entanto, a orientar-se e a concentrar-se na organização da base, descurando, ou não prestando suficiente atenção aos níveis de organização nacional e internacional (Lopes, 1999; Taylor, 2001).

Em geral têm conflitos com o setor da economia política do próprio país e com o sistema internacional, organizado na base de uma lógica moderna. Por outro lado, muitas vezes os esforços representam um nível de idealismo heroico e de sacrifício pessoal, que não é fácil suster por muito tempo. Este idealismo torna-se uma "utopia radical", tendência mais visível nos aliados provenientes do setor intelectual universitário.

\subsection{O Caminho da Negociação Cultural}

Até esta altura os principais modelos de desenvolvimento: modernização; independência nacional e aliança popular eram reconhecidos por peritos como possíveis "ingredientes" do 
desenvolvimento. No entanto, já durante os anos 70 começou a "guerra" entre estes modelos, porque cada um defendia a sua própria orientação como o único caminho válido e necessário para o desenvolvimento (Nunes, 2001; Todaro 1989).

A partir desta data, todos os congressos sobre o desenvolvimento, nos livros de texto, agências de desenvolvimento começam a reconhecer erros e limitações associadas às suas teorias. Antes de 1973, havia um ambiente de otimismo em relação ao desenvolvimento: As taxas de crescimento económico eram relativamente altas, o idealismo das novas nações tornava-se muito mais evidente do que a ineficiência ou a corrupção. $\mathrm{O}$ preço dos produtos dos países subdesenvolvidos eram de certo modo altos, em parte porque em todos os países depois da Segunda Guerra Mundial havia crescimento económico. Mas surgem novos problemas, tais como: dívida internacional, aparecimento de cidades ingovernáveis, etc. (David, 1981; Dinis; 2006).

A OPEC (Organização dos Países exportadores de Petróleo) é um dos símbolos que representa o único e verdadeiro sucesso da "teoria" do desenvolvimento e uma das poucas ideias derivadas diretamente da teoria da independência. Este sucesso da OPEC é de certo modo simbólico porque não obstante os comentários dos peritos sobre o desenvolvimento no facto de que as crises venham dos enganos cometidos, da falta de informação, dos enormes obstáculos e da própria rigidez dos países subdesenvolvidos, é possível perceber que os problemas mais profundos e difíceis são o produto do sucesso, da lógica de um ou outro modelo do desenvolvimento (Fonseca, 2006; Giddens, 1992; Gritti \& Masini, 1981: 107 e ss.).

Estas realidades demonstraram que nenhum modelo ou caminho único é possível com a exclusão da aproximação a outros modelos. A discussão académica sobre o desenvolvimento compreendida no período entre 1960-1985, caracterizou-se essencialmente por "guerras entre os modelos". A paz nos países desenvolvidos permitiu o progresso, enquanto que a guerra nos países subdesenvolvidos é um dos principais obstáculos ao seu desenvolvimento (Boudon, 1984; 1995).

Nos anos 80 a "crise" era tão grande que muitos teóricos, estudiosos desta problemática, começaram a duvidar que o desenvolvimento pudesse representar um conceito válido em todos os sentidos. Importante, e significativa, foi também uma série de acontecimentos políticos que reforçaram o repensar dos estudiosos e os levou a considerar o desenvolvimento de uma maneira diferente.

É esta combinação da "crise na ciência do desenvolvimento" e "crise sociopolítica" que gerou um novo modelo de desenvolvimento que é 
possível resumir na "negociação cultural" com mudanças de natureza económica, social, política e cultural (Lopes, 1999; Mateus, Brito \& Martins, 1995).

A dinâmica deste modelo pretende dizer que não há um caminho único que se adapte a todas as nações. É razoável o reconhecimento em adaptações em cada sociedade, descobrindo cada uma base sólida, que integre e aceite as ideias modernas radicadas nas suas culturas. As nações estão condenadas a negociar para que se possam criar sociedades integradas nas quais todos têm direito à participação.

Depreende-se deste modelo, um novo conceito de desenvolvimento que reconhece que há um mundo mas múltiplas culturas. Ora, a exclusão de alguns grupos num primeiro nível de análise é política e económica, tratando-se de um conflito entre culturas, que conduz a nacionalismos ou a fundamentalismos que não aceitam alternativas ou uma visão que não seja a sua. Todavia, é importante a reconciliação entre os diferentes modelos de desenvolvimento porque favorecem a negociação entre as culturas de cada país e do mundo (Silva, 1985).

Este novo conceito alternativo aos modelos anteriores tem sobretudo três prioridades: a) identidade cultural, b) autossuficiência, acentua o uso de recursos locais, o uso seletivo de capital produzido, a tecnologia e assistência tecnológica da parte do estrangeiro (self reliance) e c) atenção às necessidades básicas da população materiais e culturais pondo a ênfase na dinâmica interna sobre a negociação cultural, porque se pressupõe a importância de todos na participação do processo (Nunes, 2001; Rocher, ${ }^{3}$ 1980; Taylor, 2001).

Este novo conceito insere também a integração de um plano de desenvolvimento que responda às exigências ambientais e ecológicas. $\mathrm{O}$ desenvolvimento não deve seguir uma certo processo de industrialização sem ter em conta o contexto e o ambiente natural. Não deixando de reconhecer a importância desta análise relacionada com os limites e os problemas ambientais, a extensão do artigo não nos permite o seu aprofundamento que poderá ser feito noutro momento. Deste modo, apenas quisemos recordá-los porque não é possível falarmos em desenvolvimento sem os termos também em consideração quando se analisam os aspetos económicos, políticos, culturais, com diferentes lógicas de desenvolvimento (Monteiro \& Ferreira, 2009; Fonseca, 2006).

A posição deste modelo com uma visão participativa e integrativa dos diferentes modelos teve sucesso em muitas partes do mundo é por isso um método necessário e útil para uma sociedade democrática. $\mathrm{O}$ que nos permite dizer que o desenvolvimento é um processo contínuo de democratização. 
Em certo sentido, numa análise social, podemos evidenciar que esta pode ser feita através de uma síntese dos modelos do desenvolvimento: os que seguem o caminho da modernização; da independência ou planificação social com o apoio do Estado; o da aliança popular que tem o povo na sua base e particularmente a negociação cultural porque contempla uma grande pluralidade de aproximações ao desenvolvimento não apenas nacional mas também com as repercussões que atualmente os modelos têm internacionalmente.

\section{CONSIDERAÇÕES FINAIS}

Uma primeira conclusão a que podemos chegar é que o desenvolvimento é multiforme e não existe um só modelo de desenvolvimento. Este pressuposto conduz ao uso do "método comparativo", foi o que fizemos neste texto.

Por conseguinte, o interesse foi perceber a compatibilidade e as diferenças lógicas entre os modelos analisados, mas também a importância que têm mais na sua integração e menos colocando uma única alternativa, pois a sua exclusividade é um mito, eles combinam-se e complementam-se.

Âs vezes poderemos é questionar qual o melhor modelo? A resposta não é fácil, poderá passar por termos em conta o que há de bom em todos uma vez que cada um com uma cultura própria, com os seus mesmos objetivos, convicções, procuram um melhor bem-estar das pessoas. Considerarmos apenas um é utópico e um mito nas aplicações concretas.

Portanto, o desenvolvimento integral deve planificar os micro projetos com a perspetiva do sistema macro. Ou seja, aplicar e integrar os quatro modelos de desenvolvimento. Em muitos casos, os micro projetos num determinado país têm sucesso a nível "micro" durante um certo período de tempo, mas quando se tornam mais amplos a nível regional ou nacional é difícil terem o mesmo sucesso a nível "macro". Quando avaliamos as dimensões de cada um destes quatro modelos observamos aquilo que está no centro das suas orientações, valorizando uns uma dimensão e outros outra.

Assim a dimensão económica, é defendida pelo modelo da modernização. Este preocupa-se com o aumento da produtividade, com a educação que é fundamental para compreender melhor o "contexto" histórico, ecológico, geográfico, cultural, dos sistemas de produção. Por outro lado, procura associar as novas tecnologias a uma mentalidade empreendedora com capacidade para individualizar as necessidades e criar ideias que permitem uma maior eficiência na produção. 
A dimensão política relacionada com o desenvolvimento do sistema político nacional, ou seja, a independência, tem como desafio criar um sentido do sistema que supere o localismo da cultura popular. Alerta para uma educação da consciência política, onde o conhecimento da estrutura e do funcionamento do sistema político diz respeito a todos os diferentes setores da sociedade. Por exemplo, os trabalhadores agrícolas devem conhecer o ministério da agricultura e as políticas de desenvolvimento agrícola do seu país. Há a convicção de que a participação política tem poder para mudar as estruturas injustas presentes na nação. O Estado oferece benefícios segundo as necessidades de cada um.

A dimensão da aliança popular prende-se com a organização de um movimento que tem na sua base o povo. Muitas vezes acredita-se que a libertação dos pobres só acontece na presença de um movimento nacional capaz de criar uma nova cultura pronta a dar confiança ao povo, que se deve envolver e fazer parte da organização do seu país e não excluir-se ou ser excluído.

Em muitos casos os protestos geram no povo motivações que conduzem à constituição de uma estrutura de comunicação horizontal onde o povo é o centro. Interessa criar um movimento nacional, tendo em conta o processo de educação, considerado fundamental para consolidar uma a base de organização independente e autónoma.

Portanto, o resultado deste projeto não é o aumento modesto da produtividade ou de um sistema político nacional, como tinham os modelos anteriores, mas a formação de uma estrutura de organização a partir do povo e que em certa medida permitiria constituir uma base de ação sólida com a finalidade de transformar as instituições. A estratégia deste modelo é procurar, por um lado, promover uma base de solidariedade entre as organizações, e, por outro, desenvolver o capital cultural da nação. O objetivo principal destes movimentos populares era obter do governo o reconhecimento e a legitimidade, de um sistema económico nacional, onde as infraestruturas da organização fossem controladas diretamente pela base popular.

Finalmente, a dimensão de negociação cultural. A sua dimensão coincide com o próprio nome do modelo de desenvolvimento defendido, cuja função principal passa pela sua capacidade de diálogo entre as diferentes culturas em relação à economia, à política e à cultura. Estes aspetos complementam-se, devem ser considerados parte integrante e não se dispensa ou abdica da negociação que conduz às melhores reformas. Este modelo é muito crítico do conceito de "desenvolvimento" dado pelos modelos anteriores, designadamente por colocarem a ênfase sobre na racionalidade económica como desígnio central da vida da população. 
Segundo este modelo a mobilização apenas para a produtividade sem dar espaço para outras atividades, tais como: festas, participação em eventos, celebrações, festivais, arte, pintura, música, etc. torna-se demasiado racional não contribuindo para uma maior realização nem para um melhor bem-estar das pessoas.

Este modelo embora valorize mais a cultura como elemento chave do desenvolvimento, como se torna evidente no texto, não exclui o empreendedor e o progresso da economia defendida pelo modelo da modernização, ou da independência assente no partido político único, ou ainda na aliança popular onde o protagonismo é atribuído ao povo, dá maior relevância a um esforço orientado para as negociações entre as diferentes culturas, para um desenvolvimento integral da comunidade como um todo.

Leva-nos a pensar, perante a análise feita desta tipologia que por vezes os micro projetos possam ser tempo perdido o que parece melhor deixar ao Estado o dever de se ocupar do desenvolvimento através da realização de grandes projetos. De facto, parece que todas as medidas do desenvolvimento têm sido características dos sistemas nacionais, onde a pessoa, a comunidade, as relações humanas, as dimensões qualitativas passam para um segundo plano. $\mathrm{O}$ desenvolvimento segue opções cujos fatores humanos são essenciais como o são os económicos. Compreendese, portanto, que a abordagem e as nossas escolhas neste trabalho seguissem um interesse maior, orientado para o desenvolvimento e menos crescimento. A questão é que o desenvolvimento põe em primeiro lugar a pessoa, o respeito pelos direitos humanos, não esquecendo que $\mathrm{o}$ crescimento económico é mais amigo dos grandes projetos e menos dos pequenos.

Por conseguinte não nos surpreende que uma visão harmoniosa, orgânica e integral do desenvolvimento não pode deixar de ter raízes e implicações éticas e morais. Só de facto o respeito ativo de todas as pessoas e a vontade do "bem-comum" consentem harmonizar o ter mais com o ser mais e de atingir o desenvolvimento que envolve a participação de toda a comunidade.

Assim, o desenvolvimento tem como finalidade o sucesso humano e a elevação humana de todo o povo e de todos os povos, inclui todos os aspetos que colocam a pessoa humana no centro.

O homem é um ser chamado a progredir, o progresso deve ser integral, tanto pessoal como comunitário; o desenvolvimento é natural e cultural no sentido de que esse deve ser geral - interessa a todos os povos, qualquer que seja o estado atual da sua economia; unitário porque envolve toda a humanidade e solidário - entender todo o povo e a 
comunidade mundial. Dizer que o desenvolvimento está ao serviço do Homem equivale a afirmar que esse tem sentido se for visto numa perspetiva ética.

O desenvolvimento é muito mais que a economia, implica fatores económicos, mas também físicos, psicológicos, culturais, sociais, éticos e religiosos, que prestam atenção a todas as dimensões da pessoa. Do nosso ponto de vista ainda estará para chegar um modelo de desenvolvimento que siga um caminho que não privilegie alguma dimensão em particular, em detrimento de outras, como fizeram os modelos tratados, mas que leve a tê-las todas em consideração. Só com as preocupações com o Todo o desenvolvimento integral sustentável tanto a nível nacional como internacional será atingido, porque haverá seguramente convergência de vontades e cooperação. O desenvolvimento torna-se cada vez mais necessário à sobrevivência humana.

\section{REFERÊNCIAS BIBLIOGRÁFICAS}

Abdelmalki, L. \& Courlet, C. (1996). Les nouvelles logique du développement-globalisation versus localization; Paris: Éditions L'Harmattan.

Alberoni, F. ( $\left.{ }^{6} 2000\right)$. Valores, Venda Nova: Ed. Bertrand.

Barata, J. P. M. \& Ambrósio, T. (1988). Desafios e limites da modernização, Lisboa: IED.

Boudon, R. (1984). Laplace di désordre: critique des theories du changement social, Paris: PUF.

Boudon, R. (1995). Tratado de Sociologia, Lisboa: Asa.

David, E. P. (1981). "Sviluppo, modernizzazione e industrializzazione" in Antologia di scienza política, Bologna: Mulino.

Dinis, F. (2006). Crescimento e desenvolvimento económico - modelos e agentes do processo, Lisboa: Edições Sílabo.

Fonseca, A. M. (2006). Desenvolvimento humano, Lisboa: Climepsi Editores.

Galtung, J. \& Masini, E. B. (1990). Visions of desirable societies, London: Pergamon.

Gazeneuve, J. \& Victoroff, D. ( $\left.{ }^{2} 1982\right)$. Dicionário de Sociologia, Lisboa/São Paulo: Verbo.

Giddens, A. (1992). As consequências da modernidade, Oeiras: Celta.

Giraud, P. N. (1998). A desigualdade no mundo - a economia contemporânea, Lisboa: Terramar.

GRITTI, R. \& MASINI, E. B. (1981). Società e futuro - crisi dell'ocidente, esaurimento del suo modelo di sviluppo e le possibili alternative, Roma: Città Nuova.

Inglehart, R. (2001). Modernización y posmodernización. El cambio cultural economic y politico em 43 sociedades, Madrid: CIS. 
Landes, D. (2001). A riqueza e a pobreza das nações: porque são algumas tão ricas e outras tão pobres, Lisboa: Gradiva.

Lopes, A. S. ( $\left.{ }^{5} 2001\right)$. Desenvolvimento regional, Lisboa: Fundação Calouste Gulbenkian.

Lopes, A. M. (1999). Qualidade de vida - uma problemática do desenvolvimento da sociedade [online]. (citado a 24 de Março de 2013). Disponível em: http://www.apagina.pt.

Mateus, A., Brito, B. \& Martins, V. (1995). Portugal XXI - cenários de desenvolvimento, Lisboa: Bertrand, Lda.

Monteiro, R. \& Ferreira, V. (2009). Desenvolvimento e qualidade de vida [online]. (citado a 3 de Novembro de 2010), Disponível em: http://www.arquivopintasilgo.pt.

Nunes, F. Reto, L. \& Carneiro, M. (2001). O terceiro sector em Portugal: Delimitação, caracterização e potencialidades, Lisboa: INSCOOP.

Perroux, F. (1981). A filosofia do novo desenvolvimento, Lisboa: Fundação Caloust Gulbenkiam.

Pierre, R. \& Guellec, D. (2001). AS novas teorias do crescimento, Barcelos: Ed. Civilização.

Rocher, G. ( $\left.{ }^{3} 1980\right)$. Sociologia geral, Lisboa: Ed. Presença.

Rogers, E. (1969). Modernization among peasants, New York: The Free Press.

Rostow, W.W. (1960). The stage of ecomonic grouth, Cambridge: University Press.

Silva, M. (1985). Políticas de desenvolvimento económico e social, Lisboa: IED.

Taylor, A. $\left({ }^{11} 2001\right)$. As grandes doutrinas económicas, Mem Martins: Publicações Europa América.

Todaro, M. (1989). Introdução à economia: uma visão para o terceiro mundo, Rio de Janeiro: Campus.

Toffler, A. (1984). A terceira vaga, Lisboa: Edição Livros do Brasil.

Toffler, A. (1991). Os novos poderes, Lisboa: edição Livros do Brasil. 